\title{
Forensic Medicine Relevant Trends in Hospital Admissions Because of Mental and Behavioral Disorders Due to Use of Alcohol (F10 ICD-10) in the Lower Silesia Region of Poland in the Years 2006-2012
}

\author{
Jaroslaw Drobnik ${ }^{1}$, Grzegorz Odonicz-Czarnecki ${ }^{2}$, Robert Suslo, ${ }^{1, *}$ \\ ${ }^{1}$ Public Health Department, Wroclaw University Hospital, Poland \\ ${ }^{2}$ Orthopedics and Musculoskeletal Traumatology Clinics, Poland \\ *University Clinical Hospital, Public Health Department, Poland \\ robertsuslo@gmail.com
}

\begin{abstract}
Alcohol use leads not only to physical health status deterioration but most often to many forms of mental and behavioral disorders. Data on causes of hospital admissions because of mental and behavioral disorders due to use of alcohol in the years 2006-2012, made available due to courtesy of the public healthcare insurance provider Narodowy Fundusz Zdrowia in Lower Silesia region of Poland (NFZ), were analyzed to find out the current incidence and trends in the most common and important mental and behavioral disorders secondary to alcohol use. The study proved that in the Lower Silesia region of Poland's population in the years 2006-2012 there was observed rapid progression of indicators for high risk patterns of alcohol consumption there was rapid increase in yearly hospital admissions amount due to mental and behavioral disorders due to use of alcohol, because of alcohol acute intoxication, alcohol harmful use and alcohol dependence syndrome. As the increase in high risk patterns of alcohol consumption is known to be leading to many negative effects both in the health and functioning of the society, the worsening situation in the Lower Silesia region of Poland calls for urgent public health and legal action. The forensic medicine specialists have to be aware of the currently prevailing trends in alcohols use in the region to support courts and law enforcement agencies with prompt and proper opinions.
\end{abstract}

Keywords: alcohol intoxication; public health; ethanol; forensic toxicology; forensic psychiatry

Abbreviations: NFZ - Narodowy Fundusz Zdrowia in Lower Silesia region of Poland, District Division in Wroclaw

\section{INTRODUCTION}

For a long time in the history of humanity ethanol was not considered a poison as there were no characteristic abnormalities in corpses of people dying because of this kind of intoxication - only when in the beginning of the 20th century it become possible to measure the concentration of ethanol in the blood the connection between intoxication and death could be finally proven [1]. Alcohol use leads not only to physical health status deterioration but most often also to many forms of mental and behavioral disorders [2]. Both the state and local communities tend to limit in different ways the availability of ethanol based beverages to the citizens, to the children and youth in the first place unfortunately nowadays these efforts prove more and more often to be futile [3]. The middle aged men are at the highest risk of suffering from serious complications of acute alcohol intoxication [4]. Working under influence of alcohol is banned in most professions but even physicians incidentally get caught while violating this rule [5]. Alcohol use and abuse is quite common in Western culture societies and because of this massive exposure even the rarely occurring, thus unexpected, cases of genetic conditions resulting in untypical reactions to ethanol get revealed - sometimes in very young people [6]. Physicians belonging to practically all branches of medicine have to deal with patients that show various levels of ethanol intoxication - especially those employed at the emergency medicine departments and intensive care wards but it is valid also for family doctors [7]. Patients that abuse alcohol are prone to suffer from acute trauma, often also show symptoms of ethanol dependence or 
cross-dependence on ethanol and medicinal drugs, especially sleeping drugs, and their behavior traits lead to stepping outside the law rules - including domestic violence and drunk driving ending up in traffic accidents, that need forensic medicine evaluation. As alcohol abuse can cover several serious illnesses manifestations the physician shall stay alert in contact with such patients and diagnose them with highest carefulness while documenting properly all actions that were taken [8]. The intoxications with alcohol lead quite often to life threatening complications including respiratory arrest in different mechanisms which makes it the field of interest of both anesthesiology specialists and forensic pathologists [9]. The excessive use of ethanol results in withdrawal symptoms sometimes complicated with delirium state and amnesic syndrome; ethanol can also trigger psychotic disorders manifestations [10]. In such complicated cases the coexistence of ethanol with isopropanol and acetone in blood test results can shed some light on unclear cause of exacerbated status of the patient [11].

\section{MAterials AND Methods}

Data on causes of hospital admissions because of mental and behavioral disorders due to use of alcohol in the years 2006-2012, made available due to courtesy of the public healthcare insurance provider Narodowy Fundusz Zdrowia in Lower Silesia region of Poland (NFZ), were analyzed. The aim of the study was to find out the current incidence and trends in the most common and important mental and behavioral disorders secondary to alcohol use in the analyzed period of time to facilitate the process of differential diagnostics for both clinical and forensic medicine purposes.

\section{RESUlts AND DisCUSSION}

The population of the Lower Silesia region of Poland did not change significantly in amount or age structure in the years 2006-2012, but population ageing is observed [12]. In the year 2014 the Lower Silesia population was reported to be of 2,9 million people, with $52 \%$ of them being females [13].

Reported yearly amounts of hospital admissions due to use of alcohol (F10 according to ICD-10), not otherwise specified, were raising gradually with time, and in the end of the analyzed period reached the level increased by $87,9 \%$ of its initial value, as it is shown in Figure 1. It shall be interpreted as a very disturbing signal for public health authorities as it is proving negative evolution in alcohol consumption habits in the local population.

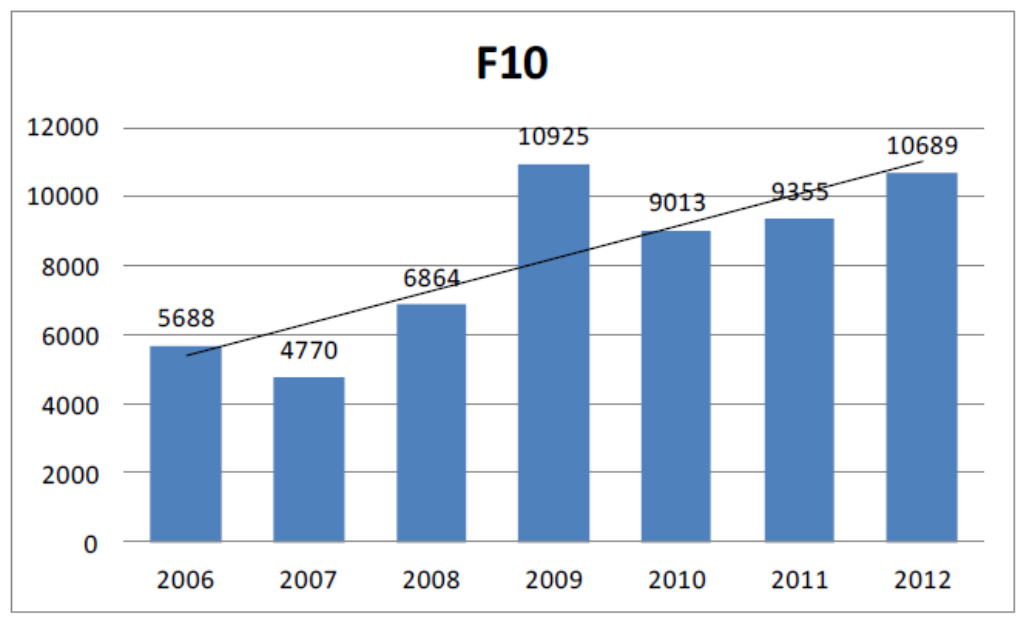

Figure1. Yearly Amounts of Admissions to Hospitals in the Lower Silesia Region of Poland in the Years 20062012 Due to Mental and Behavioral Disorders Due to Use of Alcohol (F10 According to ICD-10) Not Specified Further; Source: Data Made Available By Courtesy of the NFZ.

Acute alcohol intoxication (F10.0 according to ICD-10) cases ending up with hospital admissions were on the rise during the analyzed period and increased by $55,6 \%$ of its initial value, as it is shown in Figure 2. These data support the thesis of negative alcohol consumption habits in Lower Silesia region's population and indicates the increased burden for health services providers. 


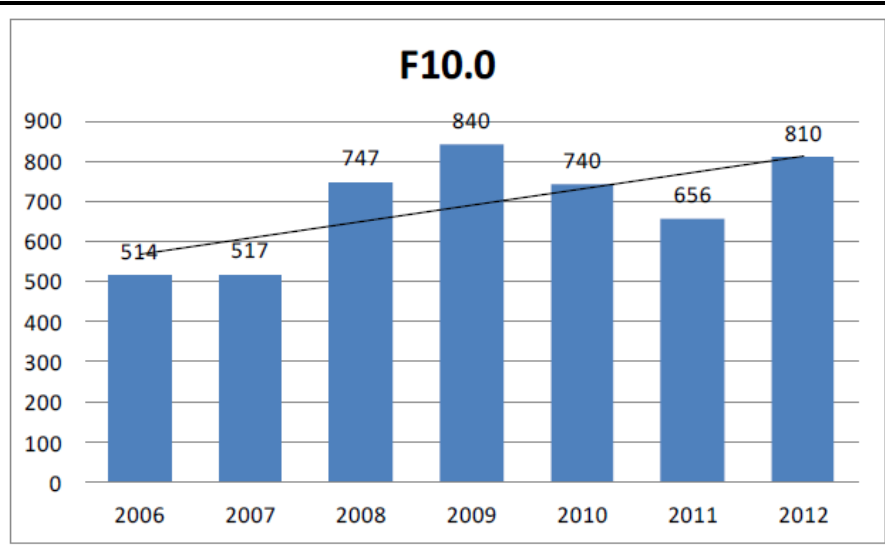

Figure2. Yearly Amounts of Admissions To Hospitals in the Lower Silesia Region of Poland in the Years 20062012 Due to Mental and Behavioral Disorders Due to Use of Alcohol - Acute Intoxication (F10.0 According to ICD-10); Source: Data Made Available by Courtesy of the NFZ.

The amount of cases of hospital admissions yearly due to harmful use of alcohol (F10.1 according to ICD-10) rose rapidly during the analyzed period by $158,3 \%$ of its initial value, as it is shown in Figure 3. Such a sign of rapid increase in risky behaviors leading to serious physical or mental damage, including depressive disorders secondary to heavy alcohol consumption, shall be the factor triggering immediate changes in local policies of alcohol related pathologies prevention.

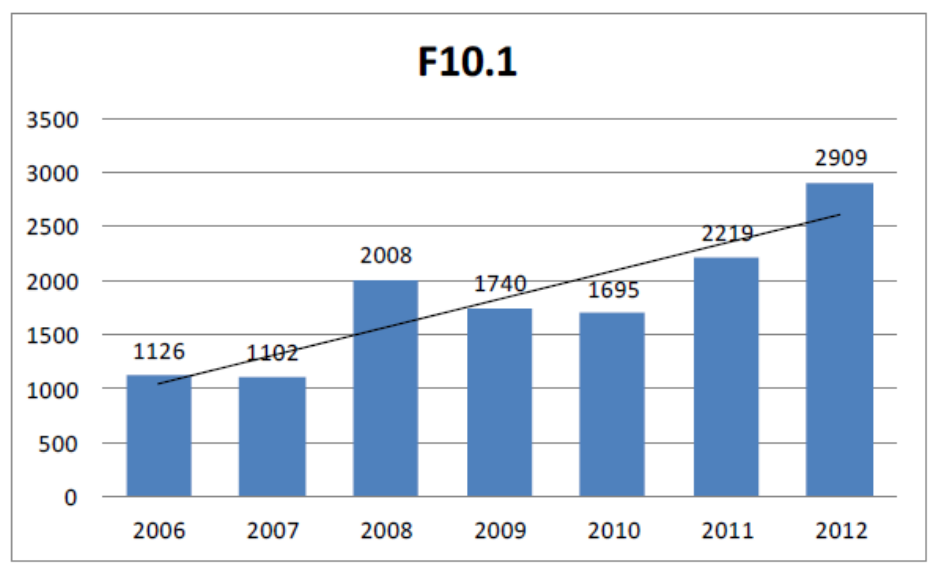

Figure3. Yearly Amounts of Admissions to Hospitals in the Lower Silesia Region of Poland in the Years 20062012 Due to Mental and Behavioral Disorders Due to Use of Alcohol - Harmful Use (F10.1 According to ICD10); Source: Data Made Available by Courtesy of the NFZ.

Alcohol dependence syndrome (F10.2 according to ICD-10) caused admissions to hospitals of Lower Silesia region of Poland increased rapidly between the years 2007 and 2008 by 73,0\% and later stayed practically unchanged, as it is demonstrated in Figure 4.

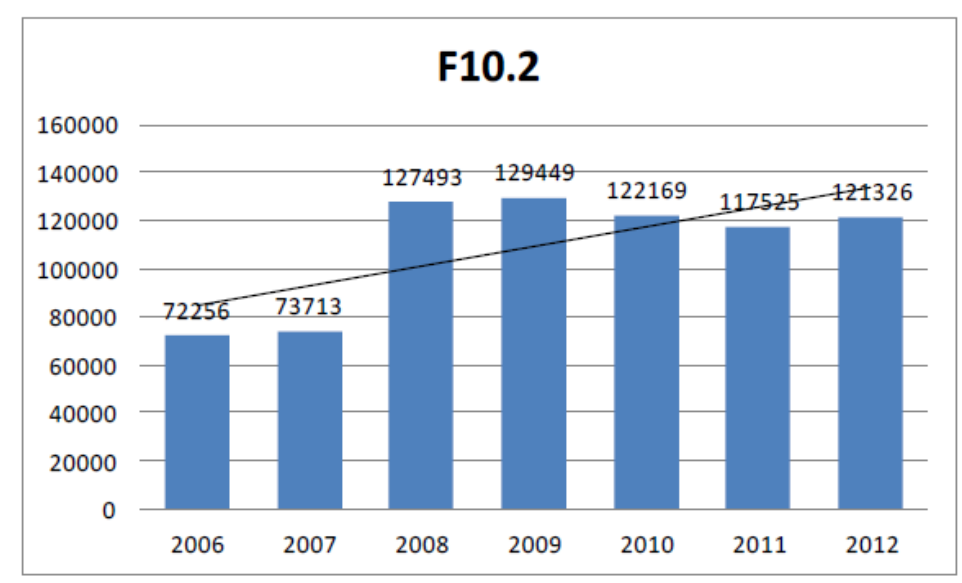

Figure4. Yearly Amounts of Admissions to Hospitals in the Lower Silesia Region of Poland in the Years 20062012 Due to Mental and Behavioral Disorders Due to Use of Alcohol - Dependence Syndrome (F10.2 According To ICD-10); Source: Data Made Available by Courtesy of the NFZ. 
The yearly amount of admissions to hospitals because of alcohol withdrawal state (F10.3 according to ICD-10) was alternating during the analyzed period, showing generally decreasing trend - finally dropping to $93,7 \%$ of its initial value, as it is showed in the Figure 5. Compared to the earlier discussed data pointing at the increase in heavy alcohol drinking, it can be at least partly attributed to development of private sector of "rapid detoxification" services at the client's house paid by the client.

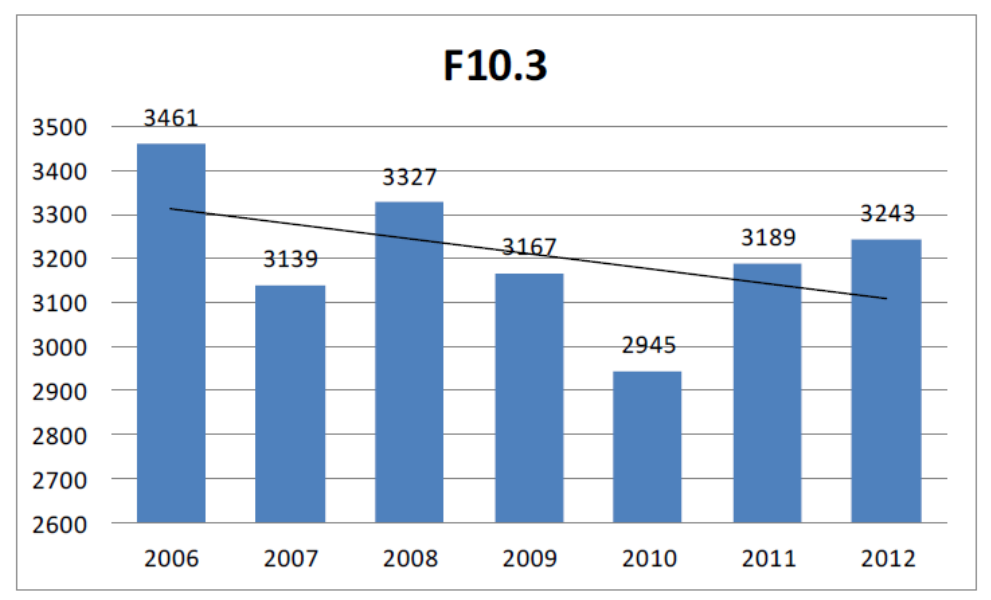

Figure5. Yearly Amounts of Admissions to Hospitals in the Lower Silesia Region of Poland in the Years 20062012 Due to Mental and Behavioral Disorders Due to Use of Alcohol - Withdrawal State (F10.3 According to ICD-10); Source: Data Made Available by Courtesy of the NFZ.

Hospital admissions caused by alcohol withdrawal state with delirium (F10.4 according to ICD-10), which are typically demanding intensive medical care, demonstrated a slight increase, by $20,0 \%$ of its initial value, as it is showed in the Figure 6.

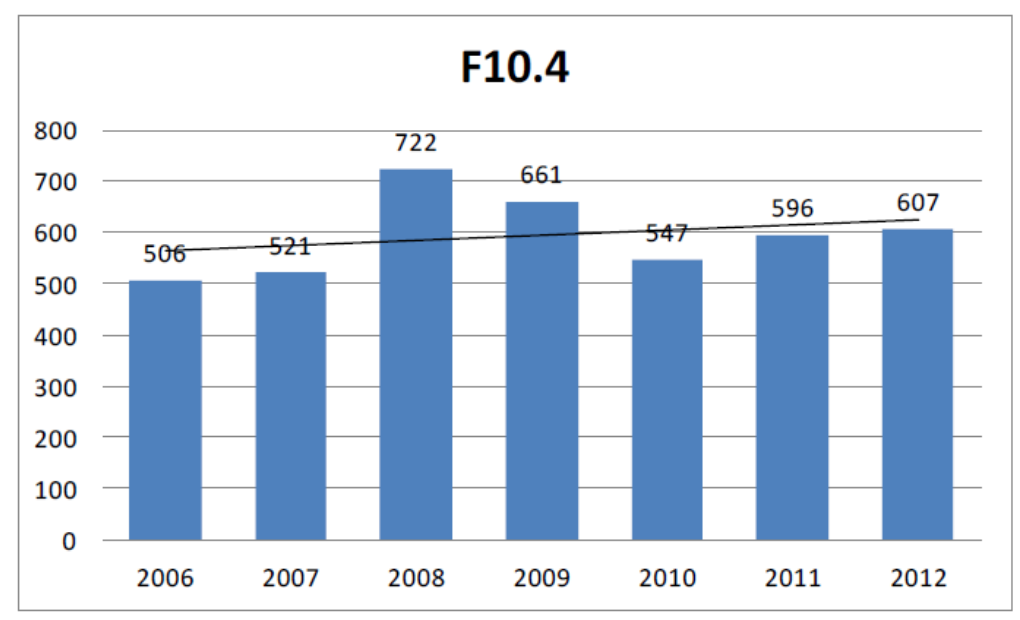

Figure6. Yearly Amounts of Admissions to Hospitals in the Lower Silesia Region of Poland in the Years 20062012 Due to Mental and Behavioral Disorders Due to Use of Alcohol - Withdrawal State with Delirium (F10.4 According to ICD-10); Source: Data Made Available by Courtesy of the NFZ.

Psychotic disorders associated with alcohol use (F10.5 according to ICD-10) were the cause of slightly decreasing amount of hospital admissions yearly and their yearly amount dropped in the analyzed period to $82,8 \%$ of its initial value, as it is demonstrated in the Figure 7 . Compared to the earlier discussed data pointing at the increase in heavy alcohol drinking, it can be at least partly attributed to development of private sector of ambulatory psychiatric and psychology services paid by patients. 


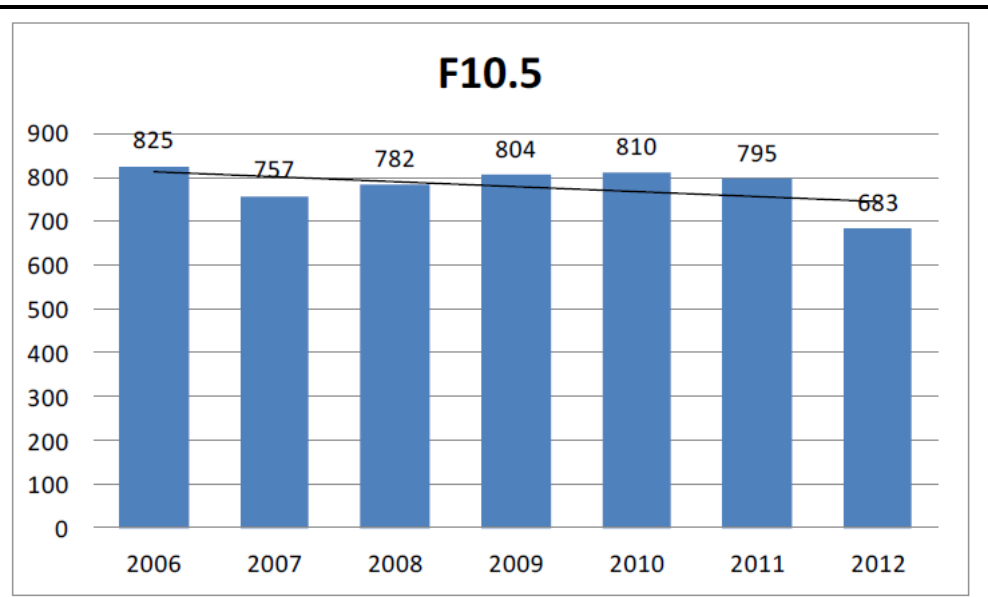

Figure7. Yearly Amounts of Admissions to Hospitals in the Lower Silesia Region of Poland in the Years 20062012 Due to Mental and Behavioral Disorders Due to Use of Alcohol - Psychotic Disorder (F10.5 According to ICD-10); Source: Data Made Available by Courtesy of the NFZ.

Amnestic syndrome due to use of alcohol (F10.6 according to ICD-10) cases needing hospital admissions increased slightly in the analyzed period, by $8,4 \%$ of its initial value, as it is illustrated by the Figure 8 .

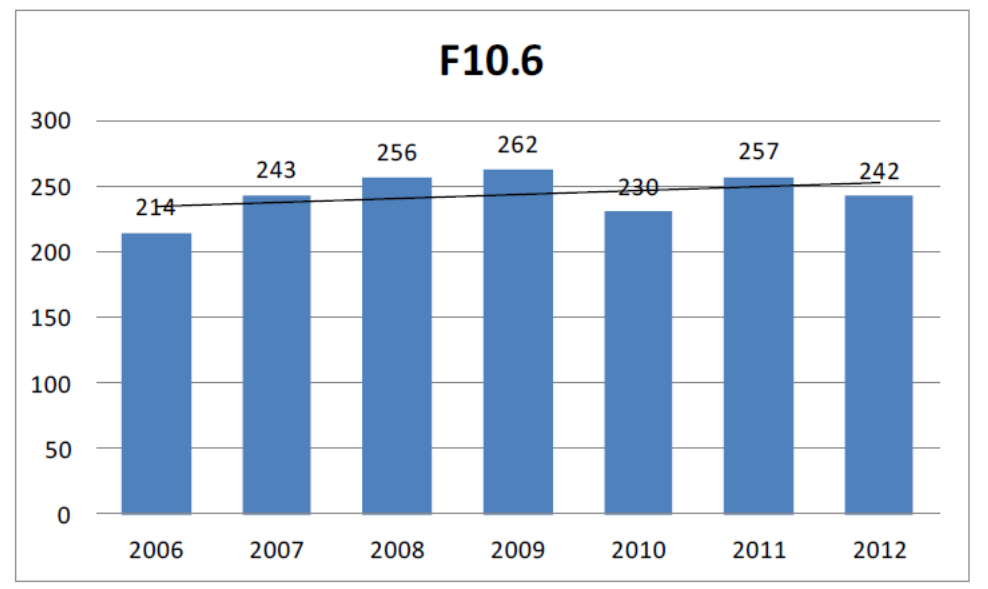

Figure8. Yearly Amounts Of Admissions to Hospitals in the Lower Silesia Region of Poland in the Years 20062012 Due to Mental and Behavioral Disorders Due to Use of Alcohol - Amnesic Syndrome (F10.6 According to ICD-10); Source: Data Made Available by Courtesy of the NFZ.

The amount of hospitalizations due to residual and late-onset disorders caused by alcohol use (F10.7 according to ICD-10) alternated in the analyzed period with general decreasing trend, reaching in the year $201286,0 \%$ of its initial value, as it is shown in the Figure 9.

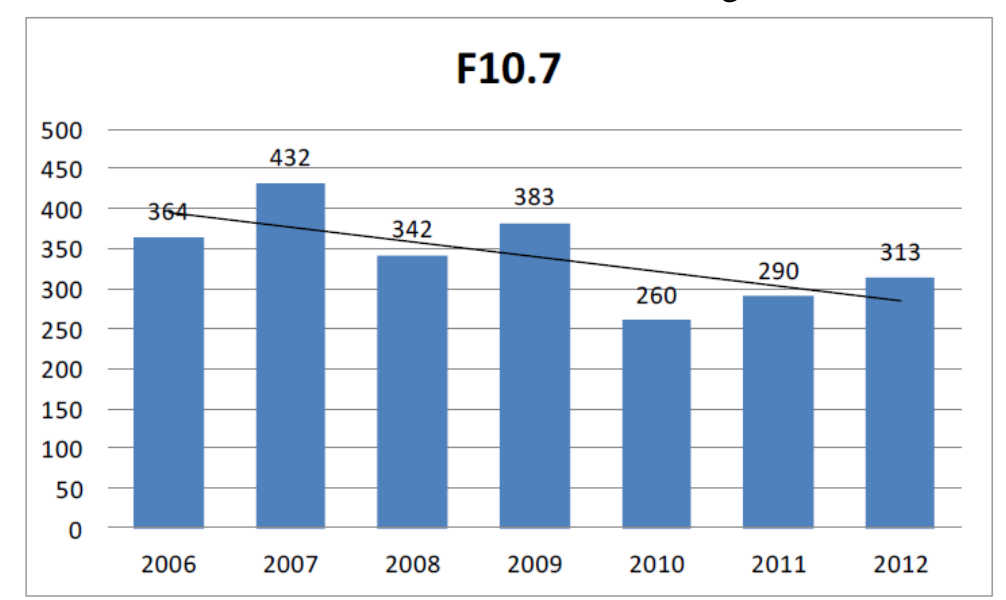

Figure9. Yearly Amounts of Admissions to Hospitals in the Lower Silesia Region of Poland in the Years 20062012 Due to Mental and Behavioral Disorders Due to Use of Alcohol - Residual and Late-Onset Disorder (F10.7 According to ICD-10); Source: Data Made Available by Courtesy of the NFZ. 
Hospital admissions ending with diagnosis of alcohol-dependent mental and behavioral disorders other then specified in the categories F10.0-F.10.7 (F10.8 according to ICD-10) dropped to 10,3\% of its initial value, as it is demonstrated in the Figure 10. This decline shall be interpreted as the mixed effect of improved hospital diagnostics and introducing by the NFZ strict formal demands for precise diagnosis before granting the hospitals payment for their services.

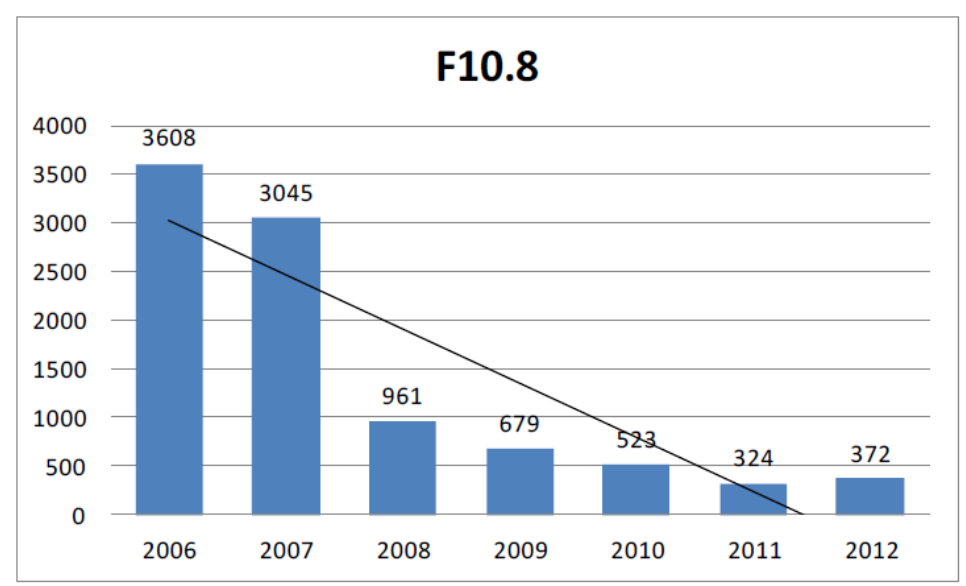

Figure10. Yearly Amounts of Admissions to Hospitals in the Lower Silesia Region of Poland in the Years 20062012 Due to Mental and Behavioral Disorders Due to Use of Alcohol - Mental and Behavioral Disorders Other Then Specified in the Categories F10.0-F.10.7 According to Icd-10 (F10.8 According To Icd-10); Source: Data Made Available by Courtesy of the Nfz.

The diagnosis of unspecified mental and behavioral disorders resulting from alcohol use (F10.9 according to ICD-10) was alternating in the analyzed period - it increased rapidly in the year 2007 to drop significantly in the year 2008 and then showed slightly decreasing trend, as it is shown in Figure 11.

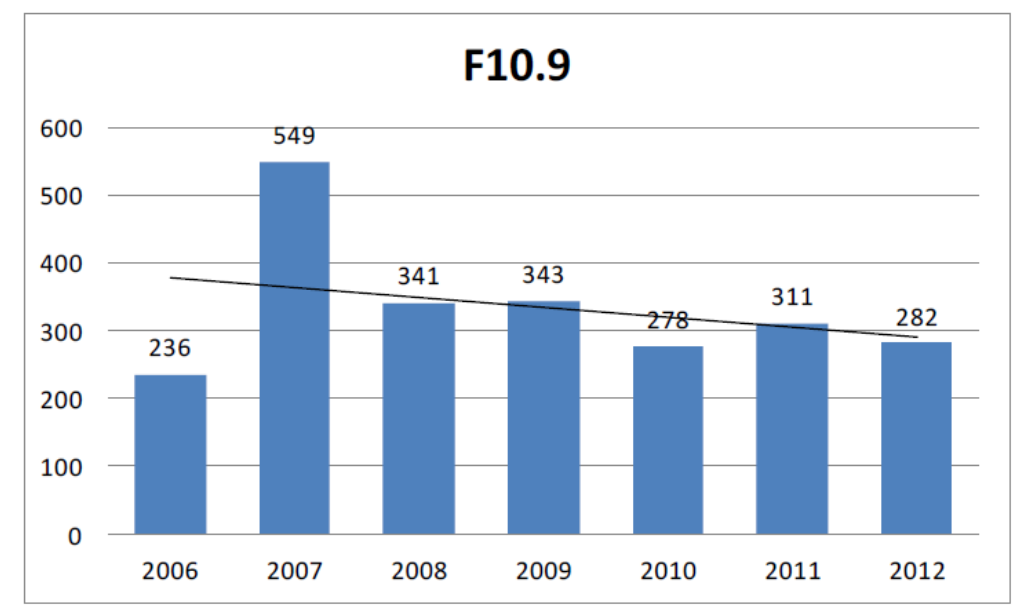

Figure11. Yearly Amounts of Admissions to Hospitals in the Lower Silesia Region of Poland in the Years 20062012 Due to Mental and Behavioral Disorders Due to Use of Alcohol - Unspecified Mental and Behavioral Disorders (F10.9 According to Icd-10); Source: Data Made Available by Courtesy of the Nfz.

\section{Conclusion}

The study has proven that in the Lower Silesia region of Poland's population in the years 2006-2012 there was observed rapid progression of indicators for high risk patterns of alcohol consumption there was rapid increase in yearly hospital admissions amount due to mental and behavioral disorders due to use of alcohol, because of alcohol acute intoxication, alcohol harmful use and alcohol dependence syndrome.

The other causes of alcohol use related hospitalizations count showed in the Lower Silesia region of Poland no significant improvement in the analyzed period. The registered decrease in hospital admissions because of withdrawal state and psychotic disorders shall be associated with development of out-of-hospital private services and not with improvement in population health status. The decrease in imprecise hospital diagnoses F10.8 according to the ICD-10 is secondary to increased formal demands of the institution paying for medical services (NFZ). 
The increase in high risk patterns of alcohol consumption is known to be leading to many negative effects: the increased burden on the shoulders of emergency medicine and intensive care facilities, increased incidence of social pathologies related phenomena, including: violence acts resulting in physical lesions, sexual and domestic violence, drunk driving with increase in traffic accidents which are the field of activity of forensic medicine. The worsening alcohol use related situation in the Lower Silesia region of Poland calls for urgent public health and legal action. The forensic medicine specialists have to be aware of the currently prevailing trends in alcohols use in the region to support courts and law enforcement agencies with prompt and proper opinions.

\section{ACKNOWLEDGMENTS}

The authors thank the NFZ for allowing them the access to the publication-relevant data.

\section{REFERENCES}

[1] Konopka T.: History of studies of alcohol toxicology; Arch. Med. Sad. Krym., 2010, LX, PP 164-171

[2] Drobnik J, Pastuszka O, Jadach R, Siwek-Jadach K, Suslo R, Pirogowicz I, Trnka J.: Negative health results of alcohol abuse; Bad.Nauk. 2007 Vol.21 nr 2; P 162

[3] Suslo R, Drobnik J.: Profilaktyka i wykrywanie uzależnień wśród dzieci i młodzieży In: Dziecko i jego środowisko: promocja zdrowia i profilaktyka chorób w pediatrii; Red. Iwona Pirogowicz, Andrzej Steciwko; Wrocław : Wydaw. Continuo, 2007; PP 135-147

[4] Oklota M, Niemcunowicz-Janica A, Zaluski J, Wardaszka Z, Ptaszynska-Sarosiek I.: Cases of acute fatal alcohol poisoning in the material of the Department of Forensic Medicine, Medical University in Bialystok, in the years 1984-2004; Arch. Med. Sad. Krym., 2009, LIX; PP 183-189

[5] Jurek T, Swiatek B, Drozd R.: Medico-legal opinionating in cases of insobriety in medical personnel; Arch.Med.Sad.Krym., 2009, LIX; PP 72-77

[6] Suslo R, Trnka J, Siewiera J, Drobnik J.: Ondine's curse - genetic and iatrogenic central hypoventilation as diagnostic options in forensic medicine; Adv.Exp.Med.Biol. 2015 Vol.861: Neuroscience and respiration. Vol.14: Respiratory health; PP 65-73

[7] Trnka J, Suslo R, Drobnik J.: Lekarz rodzinny wobec zjawiska nadużywania alkoholu przez pacjentów; Przew.Lek. 2010 nr 2; PP 184-187

[8] Suslo R, Drobnik J, Trnka J.: Rozpoznawanie i dokumentowanie przypadków przewlekłej intoksykacji wśród pacjentów podstawowej opieki zdrowotnej; Przew.Lek. 2010 nr 2; PP 180183

[9] Trnka J, Gesicki M, Suslo R, Siuta J, Drobnik J, Pirogowicz I.: Death as a result of violent asphyxia in autopsy reports; Adv.Exp.Med.Biol. 2013 Vol.788: Neurobiology of respiration; PP 413-416

[10] Suslo R, Trnka J, Filinowicz M, Drobnik J.: Zatrucia alkoholami i glikolami In: Medycyna rodzinna - co nowego? Vol.2 ; Red. Andrzej Steciwko; Wrocław: Cornetis, 2010; PP 240-243

[11] Borowska-Solonynko A, Siwinska-Ziolkowska A, Piotrkowicz M, Wysmołek M, Demkow M.: Analysis of the origin and importance of acetone and isopropanol levels in the blood of the deceased for medico-legal testimony; Arch.Med.Sad.Krym 2014; 64 (4): PP 230-2459.

[12] Drobnik J, Suslo R, Kurpas D, Trnka J.: Analysis of elderly people care system and their health needs in the Lower Silesia region; Fam.Med. Prim. Care Rev. 2010 Vol.12 no.2; PP 165-167

[13] Central Statistical Office of Poland Information Portal http://stat.gov.pl/statystykaregionalna/rankingi-statystyczne/ludnosc-wedlug-wojewodztw/ (accessed: 22.05.2016) 